\title{
Psychosomatic symptoms, social support and self worth among the elderly in Hong Kong
}

\author{
SUZANNE C HO, STUART P B DONNAN, AND APRILLE SHAM \\ From the Department of Community Medicine, The Chinese University of Hong Kong, Lek Yuen Health Centre, \\ Shatin, Hong Kong
}

SUMMARY A prospective study to test the relationship between social support and health outcomes among the 1000 elderly Chinese subjects aged $70+$ is being carried out in a Hong Kong New Town. This paper reports on the study factors related to psychosomatic complaints based on the first phase cross sectional data. Logistic regression analysis shows that being female, living in institutions, having a low level of social support and a low level of self worth independently increased the risk of developing a high level of psychosomatic symptoms. The relative risks for these factors range from 1.4 to 1.9 and all were significantly different from unity.

There has been increasing interest in the past decade on the relationship between social support and health outcomes. $^{1-4}$ Nuckolls $^{1}$ was among the earlier investigators who reported on the significant relationship between better psychosocial assets and fewer complications in pregnancy among women with life changes. Other investigators have also looked at the protective effect of social support in lowering mortality among groups of people. ${ }^{5-9}$ Blazer $^{7}$ found that social support was a significant predictor of mortality over a 30 month period among an elderly community population.

Berkman $^{2}$ postulated a number of pathways through which social support could exert its effect on health related outcomes. The advice, aids, services and economic assistance, as well as the sense of belonging, nurturance and reassurance of worth that an individual with good social support receive, are perhaps the important components through which social support is related to better health outcomes. The lack of these supports and of a sense of worth could lead to a physiologically stressful state and thus to greater susceptibility to disease and ill health. Stress could produce changes in the neural, humoral or immunological systems. ${ }^{10-12}$ Social support could be protective in serving as a buffer against stress. Some studies have found supportive interaction to be protective against the health consequences of life stress from a number of pathological states such as depression and alcoholism. ${ }^{13}$ An association between mental and physical health was found in a study by Berkman et al. ${ }^{14} \mathrm{~A}$ recent study by Goldberg et al ${ }^{15}$ has also indicated an inverse relationship between social network, support and levels of depressive symptoms in elderly women. Psychological stress could result in physiological changes in sympatheticadrenomedullary activity and could be expressed as psychosomatic symptoms.

As morbidity increases with ageing, and the aged form a fast growing segment of the population, it is important to study whether social support could help to decrease the amount of ill health and improve the quality of life among the aged in our community. As with depressive symptoms, psychosomatic complaints where psychological factors might play a decisive role have been found to be quite prevalent among the aged. ${ }^{16}$

A prospective study with the objective of testing the hypothesis that better social support is related to better health status is being carried out among the elderly in a Hong Kong New Town. This paper is based on the data collected during the first phase interview and reports on whether better social support is associated with lower level of psychosomatic complaints in the elderly. The study also attempts to define whether self worth has an independent association with the level of psychosomatic complaints. A further objective of this paper is to investigate the interrelationship between living arrangements, levels of psychosomatic complaints, social support and self worth.

\section{Methods}

A cohort study on the relationship between social support and mortality was carried out in 1036 
subjects. All subjects were aged 70 or above and were residents of Shatin New Town in the New Territories of Hong Kong. Four different sources were used in order to include subjects with different levels of social support. Forty per cent of the sample were recruited in two groups through the Old Age Allowance Scheme administered by the Shatin Social Welfare Department. (The only criteria for eligibility are age 70 and above and residence in Hong Kong for at least 5 years. A review is compulsory every 5 years to exclude subjects who have died.) The first group were recipients of the Old Age Allowance who came to the Social Welfare Department for periodic review during the study period. The second group came from a sample of one fifth of the subjects who were receiving the Old Age Allowance but were not yet due for review; these were contacted first by letter.

Another $20 \%$ of the sample was recruited from Social Centres for the elderly, and the remaining $40 \%$ came from Hostels and Homes for the elderly. Four of the six Social Centres in Shatin were selected by random sampling, and then a sampling fraction of one in three was used in the four centres for the selection of subjects.

A cross sectional analysis was carried out on the data collected in the first phase of the study. Social support referred to in this paper was measured by asking whether the subject knew anyone who could be trusted or confided in. A positive answer scored 1 and a negative answer zero. The subject was also assessed by an 8 item index on whether he or she knew anyone who would render help in different areas of need, from running errands to providing financial aid and giving guidance. A positive answer scored 1 . The scoring scale is shown in the appendix. The score for the first item (someone to trust) was multiplied by 5 to give it a heavier weighting as this specific item would probably give the subject a much better sense of psychological support. The total score for social support could thus range from 0 to 13. The level of psychosomatic symptoms was measured by an index derived from 17 items possibly experienced during the past 2 weeks; the items used were adopted from a similar WHO study. ${ }^{17}$ The symptoms included items such as difficulty in falling asleep, stomach pain, nervousness, depression, and headache. The feeling of self worth was derived from two questions about the extent to which the subjects felt forgotten or unnecessary. These two questions attempted to measure their feeling of being wanted. The answers ranged from often, sometimes, to never, and a score of 1,2 or 3 was assigned accordingly. A score of 5-6 was considered a high score on the feeling of self worth.

\section{Results}

About $30 \%$ of the subjects were residents in institutions like Old Age Homes and Hotels. One quarter lived in sheltered housing and the remainder lived in their own homes. Sheltered housing was provided by the Social Welfare Department to elderly of low socio-economic status; about 5-6 people share a flat with three bedrooms. Men accounted for about $30 \%$ of the sample. The mean age of the subjects was 76.8 years with a range from 70 to 109 .

Table 1 Length of residence in Hong Kong by sex and living arrangements (values are per cent)

\begin{tabular}{lllll}
\hline & $\begin{array}{l}\text { Normal } \\
\text { home }\end{array}$ & $\begin{array}{l}\text { Sheltered } \\
\text { housing }\end{array}$ & Institution & All \\
\hline Male & $n=206$ & $n=45$ & $n=45$ & $n=296$ \\
Since birth & 7 & 4 & 7 & 6 \\
$>50$ years & 27 & 20 & 18 & 25 \\
$31-50$ & 51 & 53 & 56 & 52 \\
$11-30$ & 10 & 22 & 18 & 13 \\
10 or less & 3 & 0 & 2 & 3 \\
& $n=290$ & $n=159$ & $n=290$ & $n=739$ \\
Female & 5 & 3 & 4 & 4 \\
Since birth & 20 & 21 & 24 & 22 \\
$>50$ years & 43 & 54 & 37 & 43 \\
$31-50$ & 25 & 20 & 23 & 23 \\
$11-30$ & 7 & 3 & 13 & 8 \\
10 or less & & & & \\
& & 5 & &
\end{tabular}

t Significant difference in different categories of years lived in Hong Kong among female subjects with different living arrangements, $p<0.01$ ( $\chi^{2}$ test)

* Significant difference between men and women in the categories of years resided in Hong Kong, $\mathrm{p}<0.001$ ( $\chi^{2}$ test)

Table 1 shows the years the subjects spent in Hong Kong by age and place of residence. About two thirds of the subjects had been in Hong Kong for at least 30 years, though very few were actually born in Hong Kong. All the male and $99 \%$ of the female immigrants were from China, mainly Guangdong Province which is located just north of Hong Kong. More men than women had been in Hong Kong for a long time. There was not much difference in the distribution of living arrangements among men in relation to their length of residence in Hong Kong, but more women living in sheltered housing had been in Hong Kong for a relatively short period of time.

Table 2 shows the relationship between age and the social circumstances and feeling of self worth of the subjects. More of the subjects aged $80+$ lived in institutions. Slightly more of the older women had resided in Hong Kong for a relatively short period of time. More of the younger elderly women reported better social support compared to the older ones. No difference in the length of residence in Hong Kong and social support among different age groups was found among men. No association between age and feeling of self worth was observed among both men and women . In general, however, more men than women reported good social support and self worth. 
Table 2 Distribution of social variables by sex and age group (values are per cent)

\begin{tabular}{|c|c|c|c|}
\hline & \multicolumn{3}{|c|}{ Age (years) } \\
\hline & $70-74$ & $75-79$ & $80+$ \\
\hline Male & $n=173$ & $n=78$ & $n=45$ \\
\hline \multicolumn{4}{|l|}{ Place of residenceł } \\
\hline Normal home & 75 & 71 & 51 \\
\hline Sheltered housing & 19 & 13 & 4 \\
\hline Institution & 7 & 17 & 44 \\
\hline \multicolumn{4}{|l|}{ Years in Hong Kong } \\
\hline Since birth & 6 & 9 & 4 \\
\hline $51+$ & 21 & 35 & 29 \\
\hline $31-50$ & 58 & 40 & 47 \\
\hline $11-30$ & 13 & 14 & 13 \\
\hline 10 or less & 2 & 3 & 7 \\
\hline \multicolumn{4}{|l|}{ Social support } \\
\hline $0-2$ & 18 & 24 & 25 \\
\hline $2 \cdot 5-7$ & 25 & 18 & 20 \\
\hline $7 \cdot 5$ & 57 & 58 & 55 \\
\hline \multicolumn{4}{|l|}{ Self worth } \\
\hline$<5$ & 31 & 38 & 36 \\
\hline $5-6$ & 69 & 62 & 64 \\
\hline Female & $n=285$ & $n=216$ & $n=245$ \\
\hline \multicolumn{4}{|l|}{ Place of residencet } \\
\hline Normal home & 56 & 41 & 20 \\
\hline Sheltered housing & 30 & 21 & 11 \\
\hline Institution & 14 & 38 & 69 \\
\hline \multicolumn{4}{|l|}{ Years in Hong Kong ${ }^{\prime}$} \\
\hline Since birth & 4 & 5 & 2 \\
\hline $51+$ & 21 & 20 & 30 \\
\hline $31-50$ & 48 & 44 & 32 \\
\hline $11-30$ & 21 & 25 & 24 \\
\hline 10 or less & 6 & 6 & 11 \\
\hline \multicolumn{4}{|l|}{ Social support * } \\
\hline $0-2$ & 26 & 27 & 29 \\
\hline $2 \cdot 5-7$ & 29 & 31 & 39 \\
\hline $7 \cdot 5+$ & 45 & 43 & 32 \\
\hline \multicolumn{4}{|l|}{ Self worth } \\
\hline$<5$ & 47 & 45 & 49 \\
\hline $5-6$ & 53 & 55 & 51 \\
\hline
\end{tabular}

Difference in the distribution of subjects within the same sex in the different categories of the indicated variables: ${ }^{*} p=0.05 ; \uparrow p<0.01 ; \neq p<0.001$ ( $\chi^{2}$ test)

Overall $81 \%$ of the respondents had experienced one or more psychosomatic symptom in the previous 2 weeks. Table 3 shows the distribution of the reported psychosomatic symptoms broken down by sex and the other variables studied such as place of residence, level of social support, and self worth. Women in general had higher complaints of psychosomatic symptoms and elderly women living in institutions had significantly more complaints. No significant trend of association between level of psychosomatic complaints and age was found. More psychosomatic complaints were found among the elderly of both sexes with low levels of social support and self worth.
Table 3 Distribution of subjects by levels of psychosomatic complaints and studied variables. Values are per cent of subjects within specified level of social support reporting high level of self worth

\begin{tabular}{|c|c|c|c|c|}
\hline & \multicolumn{4}{|c|}{ Psychosomatic symptoms } \\
\hline & None & $\leqslant 2$ & $3-7$ & $8+$ \\
\hline \multicolumn{5}{|l|}{ Male } \\
\hline \multicolumn{5}{|l|}{ Age (years) } \\
\hline $70-74$ & 173 & 58 & 22 & 20 \\
\hline $75-79$ & 78 & 53 & 26 & 22 \\
\hline $80+$ & 44 & 43 & 34 & 23 \\
\hline \multicolumn{5}{|l|}{ Residence } \\
\hline Normal home & 207 & 57 & 25 & 19 \\
\hline Sheltered housing & 45 & 60 & 18 & 22 \\
\hline Institution & 44 & 36 & 32 & 32 \\
\hline \multicolumn{5}{|l|}{ Social support* } \\
\hline $0-2$ & 62 & 45 & 23 & 32 \\
\hline $2 \cdot 5-7$ & 68 & 44 & 31 & 25 \\
\hline $7.5+$ & 168 & 61 & 23 & 16 \\
\hline \multicolumn{5}{|l|}{ Self worth* } \\
\hline$<5$ & 100 & 44 & 29 & 27 \\
\hline $5-6$ & 198 & 59 & 22 & 19 \\
\hline \multicolumn{5}{|l|}{ Female } \\
\hline \multicolumn{5}{|l|}{ Age } \\
\hline $70-74$ & 284 & 36 & 28 & 36 \\
\hline $75-79$ & 214 & 32 & 39 & 29 \\
\hline $80+$ & 227 & 24 & 40 & 36 \\
\hline \multicolumn{5}{|l|}{ Residence } \\
\hline Normal home & 295 & 38 & 32 & 30 \\
\hline Sheltered housing & 161 & 39 & 32 & 29 \\
\hline Institution & 274 & 18 & 40 & 42 \\
\hline \multicolumn{5}{|l|}{ Social support† } \\
\hline $0-2$ & 198 & 36 & 31 & 33 \\
\hline $2 \cdot 5-7$ & 235 & 22 & 37 & 42 \\
\hline $7.5+$ & 290 & 35 & 36 & 29 \\
\hline \multicolumn{5}{|l|}{ Self wortht } \\
\hline$<5$ & 339 & 27 & 33 & 41 \\
\hline $5-6$ & 384 & 35 & 37 & 28 \\
\hline
\end{tabular}

Difference in distribution of level of psychosomatic complaints among the different levels of the specified variable: ${ }^{*} p<0.05 ; \dagger p<0.01 ; \pm p<0.001$ $\left(\chi^{2}\right.$ test $)$

Table 4 Relationship between social support and self worth by sex and age group (per cent subjects with high level of self worth within specified level of social support)

\begin{tabular}{|c|c|c|c|c|c|c|c|c|}
\hline & \multicolumn{8}{|c|}{ Age group (years) } \\
\hline & \multicolumn{2}{|c|}{$7074^{*}$} & \multicolumn{2}{|c|}{7579} & \multicolumn{2}{|c|}{$80+$} & \multicolumn{2}{|l|}{ Allt } \\
\hline & $n$ & $\%$ & $n$ & $\%$ & $n$ & $\%$ & $n$ & $\%$ \\
\hline \multicolumn{9}{|l|}{ Male } \\
\hline Social support: $0-2$ & 31 & 68 & 19 & 53 & 11 & 73 & 61 & 63 \\
\hline $2 \cdot 5-7$ & 44 & 57 & 14 & 64 & 9 & 67 & 67 & 60 \\
\hline $7 \cdot 5+$ & 98 & 76 & 45 & 64 & 24 & 58 & 168 & 70 \\
\hline \multicolumn{9}{|l|}{ Female } \\
\hline Social support: 0-2 & 74 & 42 & 57 & 44 & 65 & 46 & 199 & 44 \\
\hline 2.57 & 82 & 54 & 66 & 62 & 85 & 55 & 234 & 57 \\
\hline $7 \cdot 5+$ & 126 & 60 & 91 & 56 & 72 & 50 & 290 & 57 \\
\hline \multicolumn{9}{|c|}{$\begin{array}{l}\text { Significant difference in females between distribution of proportion of levels of } \\
\text { self worth among different levels of social support, } p<0.05 ; t p<0.01 \text { ( } \chi^{2} \text { test) }\end{array}$} \\
\hline
\end{tabular}


Table 4 shows the relationship between social support and self worth. Better social support did not seem to contribute to a greater feeling of self worth among men. Among the younger elderly women, a higher proportion with high social support reported a good level of self worth.

Table 5 Relationship of feeling of self worth and psychosomatic symptoms, controlling for sex and levels of social support. Values are per cent subjects in each symptom score category

\begin{tabular}{|c|c|c|c|}
\hline & \multicolumn{3}{|c|}{ Psychosomatic symptom score } \\
\hline & $0-2$ & $3-7$ & $8+$ \\
\hline \multicolumn{4}{|l|}{ Male } \\
\hline \multicolumn{4}{|l|}{ Low social support } \\
\hline Self worth-high $(n=39)$ & 46 & 23 & 31 \\
\hline Low $(n=23)$ & 44 & 22 & 35 \\
\hline \multicolumn{4}{|l|}{ Medium social support } \\
\hline Self worth-high $(n=41)$ & 44 & 29 & 27 \\
\hline Low $(n=27)$ & 44 & 33 & 22 \\
\hline \multicolumn{4}{|l|}{ High social support* } \\
\hline Self worth-high $(\mathrm{n}=118)$ & 69 & 20 & 12 \\
\hline Low $(n=50)$ & 44 & 30 & 26 \\
\hline \multicolumn{4}{|l|}{ Female } \\
\hline \multicolumn{4}{|l|}{ Low social support } \\
\hline Self worth-high $(n=87)$ & 39 & 31 & 30 \\
\hline Low $(n=111)$ & 33 & 32 & 35 \\
\hline \multicolumn{4}{|l|}{ Medium social support } \\
\hline Self worth-high $(n=133)$ & 24 & 39 & 37 \\
\hline Low $(n=101)$ & 19 & 34 & 48 \\
\hline \multicolumn{4}{|l|}{ High social support* } \\
\hline Self worth-high $(n=164)$ & 41 & 39 & 20 \\
\hline Low $(n=126)$ & 27 & 33 & 41 \\
\hline
\end{tabular}

* High self worth $v$ low self worth, $p<0.01\left(\chi^{2}\right.$ test $)$

Table 5 shows the relationship of self worth with psychosomatic complaints when controlled for the level of social support. Psychosomatic complaints were found to be significantly lower only among men with high social support and high self worth. Women with good self worth had fewer psychosomatic complaints within the various categories of social support but this only reached significance in the high social support category.

An attempt was made to see whether there was any association between the level of self worth and social support and the place of residence. Table 6 shows that significantly more subjects of both sexes who lived in institutions reported better levels of self worth than did those with other living arrangements. A comparatively lower proportion of elderly people living in sheltered housing reported high levels of self worth. On the other hand, men and women living in their own homes seem to have better social support than those in sheltered housing and in institutions. The difference was statistically significant by $\chi^{2}$ test. The trend was similar across all age groups.
Table 6 Distribution of subjects with high level of self worth by place of residence (values are per cent)

\begin{tabular}{llll} 
Social supportt & \\
$\begin{array}{l}\text { High level } \\
\text { of self } \\
\text { worth }\end{array}$ & Low $\quad$ Medium High \\
\hline
\end{tabular}

Male

Place of residence

Normal home $(n=207) \quad 66$

Sheltered housing $(n=45) \quad 53$

Institution $(n=44)$

82

8
51
50

8
51
50

22
20
32

70

Female

Place of residence

Normal home $(n=294) \quad 53$

Sheltered housing $(n=159) 41$

Institution $(\mathbf{n}=271)$

61

11

23
33

34

42

66

20
24

Significant difference between the distribution of the variable among subjects with different housing arrangements: ${ }^{*} p<0.05$ (males); $\dagger p<0.001$ (females); $\pm \mathrm{p}<0.001$ (males and females)

Table 7 Adjusted relative risk of reporting high score of psychosomatic symptoms $(C I=$ confidence interval). Dependent variable: psychosomatic symptoms $0=0-7$; $1=8+$

\begin{tabular}{lll}
\hline Variable & $R R$ & $95 \% C I$ \\
\hline Age (per 10 years' increase) & 0.83 & $0.63-1.09$ \\
Sex: female/male & 1.53 & $1 \cdot 10-2.14$ \\
$\begin{array}{l}\text { Place of living: } \\
\quad \text { institution/non-institution }\end{array}$ & 1.91 & $1.35-2.72$ \\
Social support: low/high & 1.37 & $1.02-1.84$ \\
Self worth: low/high & 1.84 & $1.39-2.94$ \\
\hline
\end{tabular}

A logistic regression model was used to calculate the relative risk of each of the variables when adjusted for the presence of the other variables (Table 7). Being female, living in institutions, having a low level of social support and having a low level of self worth independently increased the risk of high psychosomatic complaints. Though the relative risks range only between 1.4 to 1.9 , they are all significantly different from one, with the sole exception of age.

\section{Discussion}

About $30 \%$ of our sample were living in homes for the elderly and this proportion is much higher when compared to the $4 \%$ of institutionalised elderly in Hong Kong. The waiting lists for the residential homes were long and the proportion living in institutions would increase substantially if more places were available. However, the high proportion of institutionalised elderly in our study was meant to include a substantial proportion of elderly subjects with a relatively low level of social support in order to investigate the relationship between social support and subsequent health outcomes. Our study sample also had an over representation of the aged living in 
sheltered housing, since Shatin New Town where the study was based had been chosen by the Social Welfare Department to launch the relatively new scheme of sheltered housing for the aged.

About $30 \%$ of the sample were men. This proportion is rather lower than the $38 \%$ and $34 \%$ of men in the Hong Kong and Shatin New Town populations of 70 years and over. ${ }^{16}$ The smaller proportion of elderly men in our sample is probably due to the inclusion of a high proportion of the institutionalised aged who were generally older and were mainly female subjects.

Hong Kong has a large immigrant population as there was a great influx of immigrants after the Second World War and around 1949, when mainland China became the People's Republic of China. The 1986 by-census shows that only $59 \%$ of the population were born in Hong Kong. ${ }^{16}$ These were mainly the younger age group, while a large proportion of the older population were born in China. Our study sample were mostly immigrants from Guangdong Province but had been settled in Hong Kong for many years. It is conceivable that many, especially those living in the Old Age Homes and Hostels, would have close family members residing in mainland China rather than (or in addition to) those residing in Hong Kong.

Over $80 \%$ of the subjects had experienced one or more of the 17 psychosomatic symptoms. This figure is comparable to the WHO Eleven Countries Study which also revealed high prevalence rates of complaints among the elderly. Except in Kuwait, $45-89 \%$ of elderly subjects in all areas studied reported that they had experienced some of these symptoms, either often or continuously, during the past 2 weeks. ${ }^{17}$

The psychosomatic symptoms were diffuse in nature and were grouped together to serve as a reflection of the subjects' health where it might be influenced by psychological status. A good level of social support was found to be associated with a low level of psychosomatic complaints among both elderly men and women in the present study. A similar inverse relationship was also observed for self worth. Our results agree with Goldberg's study, which reported that elderly women with good social networks and social support were less likely to have a high level of depressive symptoms. ${ }^{15}$ Berkman has suggested that good social support increases self esteem and a sense of worth. $^{2}$ The present study shows that social support seems to be important in contributing to a sense of self worth among women, but not necessarily among men. The pathways or components contributing to the sense of self worth may be different between men and women. However, among both sexes, those with good social support and a good sense of self worth experienced many fewer psychosomatic problems and less ill health.
More subjects living in institutions showed a high level of self worth. Frequent activities like visits and outings are organised by voluntary groups for these institutions. These activities may help to remind the elderly living in the Old Age Homes and Hostels that they have not been forgotten by society. In comparison the elderly living in their own homes were more likely to feel forgotten or unnecessary. The hectic lifestyle of urban living in Hong Kong may allow the younger household members little time for their elderly; and the activities organised by voluntary groups seldom involve the aged residing in their own homes unless they were members of a community group. However, the elderly living in their own homes reported a much better level of social support than those living in institutions and sheltered housing. Organised activities are usually not aimed at providing personal social support for the residents living in institutions. On the other hand, elderly people living in their own homes would probably receive support from household members or relations when there was need. The study reveals that old people living in sheltered housing and institutions in Hong Kong belong to a high risk group with low levels of social support. More of the elderly in institutions expressed high levels of psychosomatic complaints and the situation was more acute among women. Perhaps the provision of support of a more personal nature would help to improve the health of this group of elderly people.

The results discussed in this paper are based on the cross sectional analysis of the first phase interview of an on-going cohort study aimed at investigating the relationship between social support and health outcomes. The cross sectional nature of the present analysis imposes limitations on the assessment of the time sequence of social support and ill health. It is not certain whether those elderly people who are more prone to psychosomatic complaints also tend to alienate themselves and are thus less likely to maintain good relationships with members of their social group and to receive social support. The temporal relationship will have to be further investigated and confirmed in our on-going prospective study. It is also important to delineate further the individual components of social support and social networks in order to identify the most important elements contributing to good health. The results would also provide valuable information for intervention measures which could provide or help to preserve the specific elements which act to improve the quality of life among the elderly population. Having identified the high risk group and the factors which are likely to be protective, it would be important to test whether the provision or the increase of social support would suppress the level of psychosomatic complaints and thereby improve the quality of life among this group of 
elderly people. It is also important to evaluate the provision of activities which would preserve and increase the feeling of self worth among the aged.

The project is supported partially by the UPGC Grant of Hong Kong. The authors wish to thank the Social Welfare Department of the Shatin District Office, and Homes and Hostels for the elderly in Shatin for their cooperation and assistance in the study.

Address for correspondence and reprints: Dr Suzanne C Ho, Department of Community Medicine, The Chinese University of Hong Kong, 4th Floor, Lek Yuen Health Centre, Shatin, Hong Kong.

\section{References}

${ }^{1}$ Nuckolls KB, Cassel J, Kaplan BH. Psychosocial assets, life crisis and the prognosis of pregnancy. Am J Epidemiol 1972; 95: 431-41.

2 Berkman LF. Assessing the physical health effects of social networks and social support. Annu Rev Public Health 1984; 5: 413-32.

${ }^{3}$ Myers JK, Lindenthal JJ, Pepper MP. Life events, social integration and psychiatric symptomatology. $J$ Health Soc Behav 1975; 16: 421-30.

${ }^{4}$ Gore S. The effect of social support in moderating the health consequences of unemployment. J Health Soc Behav 1978; 19: 157-65.

5 Berkman LF, Syme SL. Social networks, host resistance and mortality: a nine-year follow-up study of Alameda County residents. Am J Epidemiol 1979; 109: 186-204.

${ }^{6}$ House JS, Robbins C, Metzner HL. The association of social relationships and activities with mortality: prospective evidence from the Tecumseh Community Health Study. Am J Epidemiol 1982; 115: 6-94.

${ }^{7}$ Blazer DG. Social support and mortality in an elderly community population. Am J Epidemiol 1982; 115: 686-94.
${ }^{8}$ Parkes N, Benjamin B, Fitzgerald RE. Broken heart: A study of increased mortality among widowers. $\mathrm{Br} \mathrm{Med} J$ 1969; i: 740 .

${ }^{9}$ Schoenbach VJ, Kaplan BJ, Fredman L, et al. Social ties and mortality in Evans County, Georgia. Am J Epidemiol 1986; 123: 577-91.

${ }^{10}$ Buell J, Eliot RS. The role of emotional stress in the development of heart disease. JAMA 1979; 242: 365-68.

${ }^{11}$ Calhoun JB. Population density and social pathology. Sci Am 1962; 206: 139-48.

12 Haynes S, Feinleib M. Women, work and coronary heart disease: Prospective findings from the Framingham Heart Study. Am J Public Health 1980; 70: 133-41.

${ }^{13}$ Cobb S. Social support as a moderator of life stress. $J$ Psychosomatic Med 1976; 38: 300-14.

14 Berkman LF, Berkman CS, Kasl S, et al. Depressive symptoms in relation to physical health and functioning in the elderly. Am J Epidemiol 1986; 124: 372-88.

15 Goldberg El, Natta PV, Comstock GW. Depressive symptoms, social networks and social support of elderly women. Am J Epidemiol 1985; 121: 448-56.

${ }^{16}$ Census and Statistical Department (1986). Hong Kong 1986 by-census. Hong Kong.

${ }^{17}$ Heikkinen E, Waters WE, Brzezinski ZJ, eds. The elderly in eleven countries, a socio medical survey. Public health in Europe 21. Geneva: World Health Organisation, 1983.

Accepted for publication July 1988

Appendix

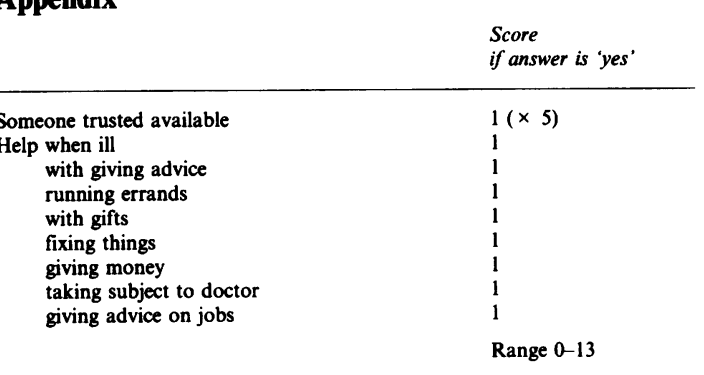

